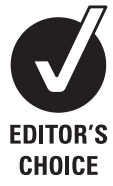

NCKU Research Center for Health Data and Institute of Public Health, College of Medicine, National Cheng Kung University, Tainan, Taiwan ${ }^{2}$ Safety Division, Institute of Transportation, Ministry of Transportation and Communications, Taipei, Taiwan ${ }^{3}$ Institute of Health Policy and Management, College of Public Health, National Taiwan University, Taipei, Taiwan

\section{Correspondence to}

Dr Tsung-Hsueh Lu, Institute of Public Health, College of Medicine, National Cheng Kung University, No. 1, Dah Hsueh Road, Tainan 701, Taiwan; robertlu@mail.ncku.edu.tw

Accepted 1 August 2011 Published Online First 2 September 2011

\title{
Reducing regional inequality in mortality from road traffic injuries through enforcement of the mandatory motorcycle helmet law in Taiwan
}

\author{
Tsung-Hsueh Lu, ${ }^{1}$ Ching-Huei Lai, ${ }^{2}$ Tung-Liang Chiang ${ }^{3}$
}

\begin{abstract}
Background This study was conducted to examine whether passage of the mandatory motorcycle helmet law in 1997 reduced the regional inequality in mortality from road traffic injuries (RTIs) across 22 cities/counties in Taiwan.
\end{abstract}

Methods We calculated the absolute (between-group variance, BGV) and relative (rate ratio between the city/ county with the highest and lowest rate, RR) terms of inequality for the overall and motorcycle-related RTI mortality rates, the rate of helmet use and three other explanatory factors associated with RTI mortality at the city/county level from 1997 through 2008.

Results The BGV of the overall and motorcycle-related RTI mortality rates across the 22 cities/counties showed persistently decreasing trends from 1997 to 2008; however, the RR of RTI mortality first increased and then levelled off from 2002. The decreasing trend in inequality was most prominent in males aged $0-24$ years. The $\mathrm{BGV}$ and $\mathrm{RR}$ of the rate of motorcycle helmet use decreased after passage of the law but increased from 2002 onwards

Conclusion In Taiwan, passage of the mandatory motorcycle helmet law reduced the regional inequality in RTI mortality; however, a resurgence in regional inequality in the helmet use rate years after passage of the helmet law was noted. It is therefore necessary to monitor the helmet use rate after passage of such a law to ensure the effect of a reduction in regional inequality in RTI mortality.

\section{INTRODUCTION}

Tackling inequality in health is an important part of the public policy agenda in many countries ${ }^{12}$; however, many interventions that could improve overall health might also increase inequality. ${ }^{3}$ The inverse equity hypothesis, proposed by Victora et al, is the most popular hypothesis used to explain this phenomenon. ${ }^{4}$ According to the hypothesis, new interventions will initially reach those of a higher socioeconomic position and only later filter down to those of poorer status. Inequalities in coverage, morbidity and mortality therefore increase first, followed later by a reduction when those of lower socioeconomic status gain greater access to the intervention and the minimum achievable levels of morbidity and mortality have been achieved in those of higher status.

Similarly, Tugwell et at indicated that community effectiveness is often substantially lower than efficacy owing to a staircase effect, which is the result of lower awareness, access or coverage; screening, diagnosis or targeting; compliance of providers and adherence of consumers. The poor probably experience a greater reduction in efficacy at all four steps and therefore a greater staircase effect than those of higher socioeconomic status, which results in a widening of the gap between the poorest and the richest. ${ }^{5}$ Furthermore, White et al suggested that compulsory enforced legislation interventions are less likely to result in an increase in social inequality in health than those of a voluntary behavioural change nature. ${ }^{3}$

Enforced legislations have been proposed to be very effective interventions in reducing mortality from road traffic injuries (RTIs). ${ }^{67}$ Motorcycles and other two-wheeled vehicles are the most commonly used means of transportation in many Asian countries, in which the numbers of deaths and head injuries sustained are also high. ${ }^{8}$ Using Taiwan as an example, by the end of 2009, the population was around 23 million, with 21.4 million registered motor vehicles, 14.6 million (68\%) of which were motorcycles, ${ }^{9}$ and on average, two motorcycles are owned per household in Taiwan. It was estimated that two-thirds of reported traffic crashes in 2002 involved motorcycles, and motorcycle-related deaths accounted for $55 \%$ of all traffic deaths. ${ }^{10}$

Motorcycle helmet laws ${ }^{11}$ and the enforcement of these laws ${ }^{12} 13$ have been proven to effectively reduce motorcycle head injuries, hospitalisations and deaths. A mandatory motorcycle helmet use law was passed and enforced in Taiwan in June 1997, and evaluative studies have revealed a subsequent dramatic reduction in motorcycle head injuries and deaths. ${ }^{14}{ }^{15}$ Nonetheless, little is known about the effects of enforced legislation on inequality in RTI mortality. The aim of this study was therefore to examine whether there was a decrease in regional inequality in overall and motorcycle-related RTI mortality after the introduction of the motorcycle helmet law in Taiwan.

As ongoing monitoring of process indicators to gauge the progress of implementation by socioeconomic status is an important step in the equity effectiveness loop proposed by Tugwell et al, we further assessed the inequality in the rate of helmet use among motorcyclists across cities/ counties of differing socioeconomic development after the introduction of the motorcycle helmet law in Taiwan.

\section{METHODS}

\section{RTI mortality}

We calculated the overall and motorcycle-related RTI mortality rates in this study. Data regarding 
the overall RTI mortality of 22 cities/counties in Taiwan from 1997 through 2008 were provided by the Statistics Office, Department of Health of Taiwan. Deaths from RTI were identified using the International Classification of Diseases, Ninth Revision, codes E810-E825.

The vital registration system was established during the Japanese colonial period in the early 1900s. Every citizen in Taiwan has a unique ID number, and every district has her own Census Administration Office in charge of vital registration affairs. The coverage of mortality data in each city/county is almost complete in Taiwan, and the concordance rate of the number of deaths according to the Department of Health and that according to the Division of Census in the Ministry of Interior was $98.7 \%$ in Taiwan. ${ }^{16}$

However, the quality of reporting of road user information related to RTI sufferers is not very satisfactory in Taiwan. ${ }^{17}$ Many Taiwanese certifiers record only RTI without specifying whether the decedent was a motorcyclist or a driver of a car. Luckily, road user information is recorded in detail in the road traffic injury file of the Department of Police, ${ }^{18}$ and we therefore asked the Department of Health and the Department of Police to link the mortality file with the road traffic injury file by ID number. As the completeness of the recording of the ID numbers of persons suffering RTI in the road traffic injury file was not very satisfactory until 2001, we thus were only able to analyse reliable linked data from 2001 onwards. Motorcycle-related death was defined as death within 30 days of the road traffic injury in which the road use item was recorded as being a motorcycle. As only four-fifths of RTI deaths in the mortality file of the Department of Health could be linked to the road traffic injury file of the Department of Police, we thus used the proportion of motor- cycle-related deaths in the linked data of each city/county to estimate the motorcycle-related RTI mortality rate in each city/ county for the years 2001 through 2008.

\section{Helmet use rate}

There is no surveillance of motorcycle helmet use in Taiwan, but there exists an item in the road traffic injury file recording whether the motorcyclist was wearing a helmet. We therefore used the road traffic injury file of the Department of Police of Taiwan to estimate the rates of helmet use in each city/county from 1997 through 2008. ${ }^{18}$ In other words, we used the helmet use behaviour of persons involved in RTI events as a proxy of the helmet use behaviour of the general population.

\section{Inequality measures}

There are many kinds of inequality measures, and these can be classified into those for non-ordered variables, such as regions, ethnicities or races, etc, and those for ordered variables, such as educational achievements, income levels and occupation rankings, etc. ${ }^{19} 20$ Another important classification of inequality measures is whether the measure is in absolute terms (eg, rate difference) or in relative terms (eg, rate ratio (RR)). ${ }^{21} 22$ As region is a non-ordered variable, we therefore selected between-group variance $(\mathrm{BGV})$ as the absolute term of inequality measure in this study. BGV is the inequality measure most relevant to health policy decision-making because it incorporates the population size of each city/county. It is defined as: 1920

$$
B G V=\sum_{i=1}^{n} P_{i}\left(y_{i}-\bar{y}\right)^{2}
$$

where $P_{i}$ is the population size of the $i^{\text {th }}$ city/county,

Table 1 Selected contextual socioeconomic indicators in each city/county and percentage change between 1997 and 2008 in Taiwan

\begin{tabular}{|c|c|c|c|c|c|c|c|c|c|}
\hline & \multicolumn{3}{|c|}{ Population density (population $/ \mathbf{k m}^{2}$ ) } & \multicolumn{3}{|c|}{$\begin{array}{l}\text { Percentage of work force in primary } \\
\text { industry }\end{array}$} & \multicolumn{3}{|c|}{$\begin{array}{l}\text { Annual household disposable income } \\
\text { (US\$) }\end{array}$} \\
\hline Whole of Taiwan & 592 & 637 & 8 & 10.6 & 5.2 & -51 & 24309 & 26105 & 7 \\
\hline Taipei City & 9687 & 9650 & 0 & 0.5 & 0.3 & -33 & 34036 & 36316 & 7 \\
\hline Hsinchu City & 3269 & 3892 & 19 & 2.6 & 0.5 & -81 & 26235 & 33923 & 29 \\
\hline Keelung City & 2778 & 2930 & 5 & 1.3 & 0.6 & -53 & 23679 & 23334 & -1 \\
\hline Hsinchu County & 286 & 353 & 23 & 8.0 & 2.8 & -65 & 26367 & 30399 & 15 \\
\hline Yilan County & 218 & 215 & -1 & 10.1 & 6.9 & -32 & 22437 & 24227 & 8 \\
\hline Middle & 515 & 548 & 6 & 17.4 & 8.6 & -51 & 20144 & 22515 & 12 \\
\hline Taichung City & 5221 & 6524 & 25 & 2.2 & 0.6 & -73 & 26736 & 26184 & -2 \\
\hline Miaoli County & 308 & 308 & 0 & 12.5 & 5.2 & -58 & 23616 & 21553 & -9 \\
\hline Taichung County & 685 & 759 & 11 & 9.8 & 4.3 & -56 & 21381 & 23353 & 9 \\
\hline Kaohsiung City & 9284 & 9933 & 7 & 2.1 & 0.9 & -58 & 26093 & 27481 & 5 \\
\hline Chiayi City & 4354 & 4561 & 5 & 3.9 & 0.9 & -77 & 23615 & 21183 & -10 \\
\hline Tainan City & 4024 & 4375 & 9 & 3.5 & 1.4 & -60 & 23426 & 26294 & 12 \\
\hline Chiayi County & 298 & 289 & -3 & 32.1 & 20.5 & -36 & 18207 & 18718 & 3 \\
\hline Tainan County & 537 & 548 & & 18.7 & 10.1 & -46 & 18961 & 20847 & 10 \\
\hline Kaohsiung County & 428 & 445 & 4 & 10.8 & 6.9 & -36 & 21408 & 22289 & 4 \\
\hline Pingtung County & 329 & 319 & -3 & 24.4 & 17.0 & -30 & 21609 & 20032 & -7 \\
\hline East & 75 & 70 & -7 & 18.9 & 15.1 & -20 & 21296 & 18620 & -13 \\
\hline Hualien County & 78 & 74 & -5 & 12.1 & 9.0 & -25 & 21802 & 19858 & -9 \\
\hline Taitung County & 72 & 66 & -8 & 27.7 & 22.6 & -18 & 16311 & 16757 & 3 \\
\hline
\end{tabular}


$y_{i}$ is the mortality or helmet use rate of the $i^{\text {th }}$ city/county and $y^{-}$is the average mortality or helmet use rate of Taiwan as a whole.

We also computed the RR of the rate of the city/county with the highest and the lowest rate and the rate of the East (leastdeveloped) and North (most-developed) regions as the relative term of inequality measure.

\section{Contextual and other explanatory factors}

We selected three contextual factors to illustrate the large variations in socioeconomic development across cities/counties in Taiwan: population density (population per square kilometre), percentage of the work force in primary industry (farming, fishing, mining, etc) and annual median disposable household income (US\$). ${ }^{23}$ The percentage changes in the three indicators between 1997 and 2008 in each city/county were computed.

To explore the effects of changes in other explanatory factors that might be associated with RTI mortality, we analysed three indicators: the number of registered motorcycles per 1000 population as a proxy of road traffic exposure, the number of police-recorded RTI per 10000 population as proxy of the occurrence of RTI and the number of general beds per 10000 population as a proxy of access to hospital. ${ }^{23}$

\section{Analysis}

For overall RTI mortality, we first calculated the age-adjusted death rate for each city/county using the population structure of Taiwan for the year 2000 as the standard. The age groups used to calculate the age-adjusted rates were 0-14, 15-24, 25-44, 45-64 and 65+ years. We then computed the sex- and agespecific RTI death rates for each city/county. To avoid small numbers of deaths in some sex-age groups in some cities/ counties, we combined 3 years together, that is, 1997-1999, 2000-2002, 2003-2005 and 2006-2008.

For motorcycle-related RTI mortality, the Department of Police did not approve of providing the sex- and age-specific numbers of linked cases owing to the liability of identifying specific persons in regions with small populations. We were therefore only able to calculate the crude death rate for each city/county.

For inequality measures, we calculated the BGV and RR of the overall and motorcycle-related RTI mortality rates, helmet use rate and three other explanatory factors across 22 cities/counties for each study year to indicate the changes in inequality after the introduction of the mandatory motorcycle helmet law.

\section{RESULTS}

Huge variations in the socioeconomic contextual indicators across the 22 cities/counties were noted (table 1). Taipei City had the highest population density and household disposable income and the lowest percentage of the work force in primary industry in 1997 and 2008. On the contrary, Taitung County was the least-developed region in Taiwan in 1997 and 2008. Most cities/counties, except those in the East region, showed an increase in population density and household disposable income from 1997 to 2008.

Table 2 Mortality from overall road traffic injuries in each city/county and absolute inequality (between-group variance, BGV), relative inequality (rate ratio between the highest and lowest regions or between the east and north regions) and percentage change between 1997 and 2008 in Taiwan

\begin{tabular}{|c|c|c|c|c|c|c|c|c|c|c|c|c|c|}
\hline & 1997 & 1998 & 1999 & 2000 & 2001 & 2002 & 2003 & 2004 & 2005 & 2006 & 2007 & 2008 & Change \\
\hline Whole of Taiwan & 31 & 28 & 25 & 24 & 21 & 19 & 19 & 20 & 20 & 19 & 16 & 15 & -52 \\
\hline North & 22 & 19 & 18 & 17 & 14 & 13 & 14 & 15 & 14 & 14 & 11 & 10 & -54 \\
\hline Taipei City & 13 & 10 & 8 & 8 & 7 & 6 & 7 & 7 & 7 & 7 & 6 & 5 & -61 \\
\hline Hsinchu City & 26 & 27 & 23 & 24 & 20 & 22 & 15 & 15 & 18 & 18 & 14 & 13 & -49 \\
\hline Keelung City & 17 & 17 & 18 & 15 & 14 & 11 & 13 & 15 & 12 & 14 & 10 & 9 & -48 \\
\hline Taipei County & 19 & 16 & 13 & 14 & 11 & 10 & 11 & 12 & 12 & 12 & 10 & 9 & -53 \\
\hline Taoyuan County & 33 & 27 & 30 & 28 & 22 & 21 & 22 & 24 & 21 & 22 & 18 & 14 & -57 \\
\hline Hsinchu County & 48 & 45 & 43 & 38 & 35 & 28 & 29 & 28 & 28 & 25 & 23 & 24 & -50 \\
\hline Yilan County & 41 & 38 & 40 & 32 & 32 & 28 & 26 & 28 & 25 & 27 & 22 & 22 & -48 \\
\hline Middle & 36 & 34 & 31 & 29 & 24 & 22 & 21 & 23 & 24 & 24 & 20 & 19 & -48 \\
\hline Taichung City & 13 & 14 & 12 & 10 & 10 & 9 & 11 & 12 & 15 & 12 & 14 & 9 & -30 \\
\hline Miaoli County & 47 & 42 & 40 & 40 & 34 & 27 & 29 & 27 & 28 & 32 & 23 & 20 & -58 \\
\hline Taichung County & 34 & 28 & 20 & 21 & 14 & 14 & 16 & 19 & 21 & 22 & 19 & 17 & -52 \\
\hline Changhua County & 40 & 38 & 37 & 33 & 28 & 23 & 22 & 23 & 26 & 24 & 22 & 20 & -51 \\
\hline Nantou County & 47 & 44 & 41 & 35 & 31 & 29 & 25 & 30 & 24 & 26 & 20 & 24 & -49 \\
\hline Yunlin County & 43 & 44 & 51 & 47 & 39 & 41 & 31 & 34 & 38 & 34 & 29 & 29 & -33 \\
\hline South & 35 & 32 & 30 & 29 & 27 & 23 & 24 & 25 & 24 & 22 & 19 & 18 & -50 \\
\hline Kaohsiung City & 29 & 21 & 16 & 18 & 17 & 15 & 16 & 16 & 15 & 15 & 11 & 10 & -65 \\
\hline Chiayi City & 25 & 22 & 22 & 21 & 24 & 20 & 15 & 21 & 18 & 12 & 12 & 9 & -64 \\
\hline Tainan City & 21 & 21 & 19 & 22 & 19 & 16 & 15 & 16 & 19 & 15 & 15 & 15 & -28 \\
\hline Chiayi County & 45 & 46 & 39 & 34 & 35 & 32 & 31 & 29 & 29 & 27 & 26 & 21 & -53 \\
\hline Tainan County & 40 & 39 & 39 & 37 & 31 & 26 & 28 & 30 & 26 & 27 & 22 & 20 & -49 \\
\hline Kaohsiung County & 40 & 35 & 35 & 34 & 29 & 25 & 27 & 29 & 26 & 23 & 21 & 19 & -53 \\
\hline Pingtung County & 42 & 41 & 41 & 35 & 40 & 34 & 33 & 34 & 34 & 33 & 30 & 29 & -31 \\
\hline East & 70 & 56 & 42 & 47 & 49 & 41 & 40 & 44 & 43 & 40 & 31 & 27 & -61 \\
\hline Hualien County & 61 & 61 & 46 & 45 & 50 & 39 & 40 & 42 & 44 & 37 & 25 & 24 & -61 \\
\hline $\begin{array}{l}\text { Taitung County } \\
\text { Inequality }\end{array}$ & 81 & 48 & 38 & 51 & 48 & 43 & 41 & 46 & 42 & 43 & 38 & 32 & -61 \\
\hline BGV & 179 & 157 & 170 & 135 & 129 & 97 & 77 & 82 & 78 & 71 & 52 & 49 & \\
\hline Highest/lowest & 6.25 & 5.93 & 6.49 & 6.32 & 7.09 & 7.41 & 6.02 & 6.21 & 6.04 & 5.85 & 6.58 & 6.20 & \\
\hline East/North & 3.13 & 2.92 & 2.41 & 2.74 & 3.44 & 3.15 & 2.98 & 3.00 & 3.08 & 2.84 & 2.66 & 2.62 & \\
\hline
\end{tabular}


For each city/county, we identified a drastic reduction in the overall RTI mortality rate immediately after passage of the helmet law in 1997 (table 2). It is interesting to note that the two most prosperous metropolitans (Taipei City and Kaohsiung City) and the two least-developed counties in the East region (Hualien County and Taitung County) showed the largest decreasing trends in the overall RTI mortality rate. Nevertheless, some cities/counties (such as Taipei County, Taichung City, Taichung County and Yunlin County) did not exhibit a prominent reduction in the motorcycle-related RTI mortality rate (table 3 ).

In terms of the absolute inequality measure, the BGV of the overall and motorcycle-related RTI mortality rates across the 22 cities/counties exhibited persistently decreasing trends from 1997 to 2008 (tables 2 and 3 and figure 1). However, with regards to the relative inequality measure, the $R R$ of the overall and motorcycle-related RTI mortality rates between the city/county with the highest and the lowest rate kept on increasing after passage of the helmet law, reaching a maximum in 2002, and then levelled off (tables 2 and 3 and figure 1). The decreasing trend in inequality was most prominent in males aged $0-24$ years (table 4 ).

Table 5 reveals the estimated rate of motorcycle helmet use for each city/county in Taiwan from 1997 through 2008. The helmet use rate increased drastically from 1997 through 2002 and then levelled off, the rate for Taiwan as a whole being $93 \%$ in 2002 and decreasing to $88 \%$ in 2008. Hsingchu City, Taipei County, Miaoli County and Yunlin County had a helmet use rate lower than $80 \%$ in 2008, and Hsingchu City, Taipei County and Yunlin County showed the largest decrease in the helmet use rate from 2002 to 2008 . The absolute and relative terms of inequality in the helmet use rate decreased from 1997 to 2002 and then increased onwards.

Regarding other explanatory factors associated with mortality from RTI, we found that most cities/counties had a one-third increase in registered motorcycles per 1000 population, a onethird decrease in reported RTI per 10000 population and no prominent change in general beds per 10000 population from 1997 to 2008 (table 6). The absolute term of inequality (BGV) increased for owning a motorcycle, decreased for the occurrence of reported RTI and did not change for access to hospitals from 1997 to 2008.

\section{DISCUSSION}

The findings of this study indicate a drastic decrease in the absolute term of inequality in overall and motorcycle-related RTI mortality after passage of the motorcycle helmet law, which persisted throughout the study period. However, the relative term of inequality in RTI mortality first increased and then levelled off, as predicted by the inverse equity hypothesis proposed by Victora et al. ${ }^{4}$ With regard to the motorcycle helmet use rate, the absolute and relative terms of inequality exhibited a decreasing trend after passage of the helmet law, but an increase in inequality in the rate of helmet use was noted 5 years after passage of the law.

Table 3 Mortality from motorcycle-related road traffic injuries in each city/county and absolute inequality (between-group variance, BGV), relative inequality (rate ratio between the highest and lowest regions or between the east and north regions) and percentage change between 2001 and 2008 in Taiwan

\begin{tabular}{|c|c|c|c|c|c|c|c|c|c|}
\hline & 2001 & 2002 & 2003 & 2004 & 2005 & 2006 & 2007 & 2008 & Change \\
\hline Whole of Taiwan & 12 & 11 & 11 & 12 & 12 & 12 & 11 & 10 & -14 \\
\hline North & 7 & 7 & 7 & 8 & 8 & 8 & 7 & 6 & -11 \\
\hline Taipei City & 4 & 3 & 3 & 4 & 4 & 4 & 3 & 3 & -16 \\
\hline Hsinchu City & 13 & 12 & 8 & 9 & 10 & 11 & 11 & 9 & -30 \\
\hline Keelung City & 7 & 6 & 7 & 8 & 6 & 7 & 6 & 5 & -27 \\
\hline Taipei County & 5 & 6 & 5 & 6 & 7 & 7 & 6 & 6 & 7 \\
\hline Taoyuan County & 10 & 11 & 11 & 12 & 11 & 12 & 10 & 8 & -17 \\
\hline Hsinchu County & 17 & 15 & 14 & 15 & 16 & 14 & 15 & 14 & -16 \\
\hline Yilan County & 20 & 16 & 17 & 13 & 17 & 19 & 12 & 16 & -21 \\
\hline Middle & 13 & 14 & 12 & 15 & 16 & 15 & 13 & 13 & -7 \\
\hline Taichung City & 5 & 4 & 6 & 8 & 9 & 8 & 9 & 6 & 20 \\
\hline Miaoli County & 20 & 15 & 16 & 13 & 16 & 19 & 12 & 13 & -35 \\
\hline Taichung County & 7 & 8 & 9 & 12 & 12 & 13 & 11 & 11 & 55 \\
\hline Changhua County & 15 & 14 & 13 & 14 & 17 & 16 & 14 & 13 & -13 \\
\hline Nantou County & 17 & 17 & 14 & 16 & 13 & 15 & 12 & 16 & -8 \\
\hline Yunlin County & 20 & 28 & 19 & 23 & 22 & 24 & 22 & 20 & 3 \\
\hline South & 15 & 13 & 15 & 15 & 15 & 16 & 14 & 12 & -18 \\
\hline Kaohsiung City & 10 & 10 & 12 & 10 & 10 & 11 & 7 & 7 & -32 \\
\hline Chiayi City & 12 & 12 & 8 & 14 & 10 & 7 & 8 & 4 & -68 \\
\hline Tainan City & 11 & 8 & 9 & 10 & 13 & 9 & 11 & 11 & -5 \\
\hline Chiayi County & 21 & 18 & 18 & 17 & 16 & 17 & 19 & 15 & -29 \\
\hline Tainan County & 16 & 16 & 17 & 18 & 16 & 16 & 15 & 14 & -11 \\
\hline Kaohsiung County & 18 & 15 & 18 & 20 & 19 & 18 & 17 & 14 & -21 \\
\hline Pingtung County & 25 & 21 & 22 & 22 & 24 & 27 & 22 & 21 & -13 \\
\hline East & 25 & 24 & 24 & 26 & 24 & 28 & 21 & 18 & -25 \\
\hline Hualien County & 24 & 24 & 23 & 24 & 23 & 23 & 17 & 17 & -29 \\
\hline Taitung County & 25 & 25 & 26 & 28 & 26 & 34 & 26 & 20 & -22 \\
\hline \multicolumn{10}{|l|}{ Inequality } \\
\hline BGV & 42 & 41 & 33 & 34 & 33 & 40 & 30 & 26 & \\
\hline Highest/lowest & 6.81 & 9.83 & 7.37 & 7.25 & 6.99 & 7.69 & 7.83 & 6.97 & \\
\hline East/North & 3.41 & 3.40 & 3.43 & 3.33 & 3.09 & 3.37 & 2.97 & 2.86 & \\
\hline
\end{tabular}


Figure 1 Changes in absolute inequality (between-group variance, BGV) and relative inequality (rate ratio between the highest and lowest regions, RR) in mortality from road traffic injuries (RTIs) from 1997 through 2008 in Taiwan (left: overall RTls; right: motorcycle-related RTIs).
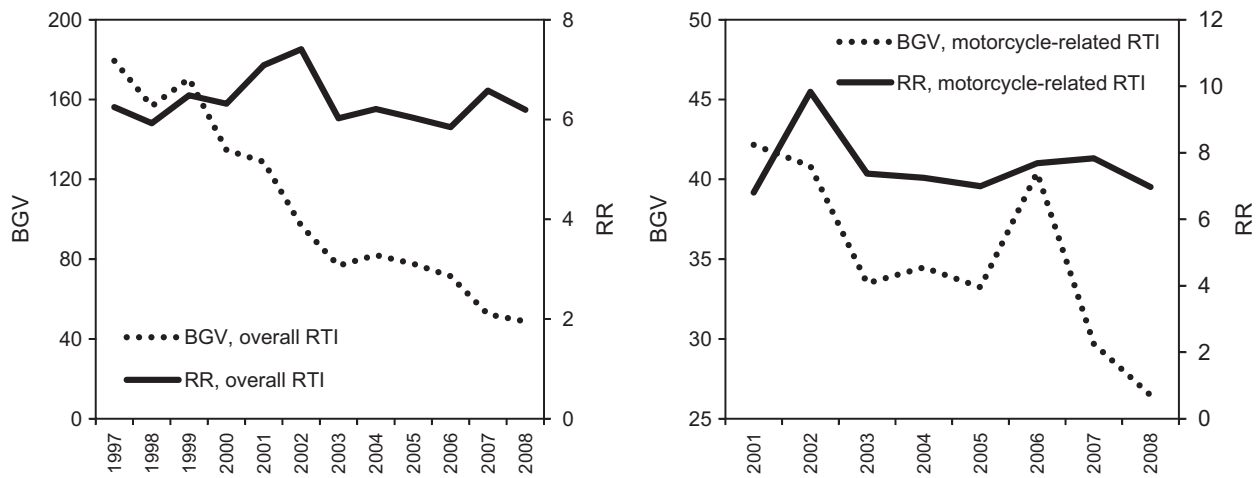

\section{Strengths and limitations}

One strength of this study was the high percentage of motorcycle use as the main method of transportation in Taiwan, which provided a good opportunity to examine the possible effects of passage of the motorcycle helmet law on reducing the regional inequality in mortality from RTI. A second strength was the examination of the rate of motorcycle helmet use in each city/county, which is the intermediate factor between passage of the motorcycle helmet law and RTI mortality. The information this study provided could enable a better understanding of the mechanisms and pathways resulting in changes in regional inequality in RTI mortality.

However, several limitations should be noted in interpreting the findings of this study. First, the motorcycle-related RTI mortality in each city/county was estimated according to linked data between the mortality file of the Department of Health and the road traffic injury file of the Department of Police, and the percentage of road traffic injury reports in which an ID number was reported might differ in different cities/counties, resulting in differing linkage rates across the various cities/counties. Furthermore, some RTI deaths recorded in the mortality file might not be reported to police officers and may therefore not be recorded in the road traffic injury file.

The second limitation was the selection of three indicators as proxies of explanatory factors associated with RTI mortality, which might not be ideal measures of the real exposure to motorcycles, incidence of RTI and access to hospitals. In addition, the changes in regional inequality in RTI mortality might be due to differential development of the road traffic infrastructure, such as the establishment of mass transit systems in Taipei City and Kaohsiung City. We also found that some cities/ counties have already reached the ceiling effect of helmet use rate (more than 95\%), but still exhibit a decrease in the RTI rate: that is to say, many other explanatory factors are working to reduce RTI mortality.

The third limitation was that the motorcycle helmet use rate in each city/county might be underestimated because the estimation was based on the helmet use rate among motorcyclists suffering RTI reported to the police. As many RTIs involve violation of traffic laws, it is reasonable to hypothesise that people who violated some traffic laws might be less compliant with the motorcycle helmet law.

Table 4 Absolute inequality (between-group variance, BGV) and percentage change between 1997-1999 and 2006-2008 and relative inequality (rate ratio between the highest and lowest regions, RR) in mortality from overall road traffic injuries by sex and age in Taiwan

\begin{tabular}{|c|c|c|c|c|c|c|c|c|c|c|}
\hline & \multicolumn{5}{|l|}{ BGV } & \multicolumn{5}{|l|}{ RR } \\
\hline & 1997-1999 & $2000-2002$ & $2003-2005$ & $2006-2008$ & Change & 1997-1999 & $2000-2002$ & $2003-2005$ & $2006-2008$ & Change \\
\hline \multicolumn{11}{|c|}{ Males and females } \\
\hline $15-24 \mathrm{yr}$ & 223 & 165 & 91 & 57 & -74 & 4.6 & 4.4 & 3.9 & 3.3 & -28 \\
\hline $25-44 \mathrm{yr}$ & 139 & 91 & 66 & 52 & -63 & 6.6 & 9.2 & 7.8 & 8.6 & 30 \\
\hline $45-64 \mathrm{yr}$ & 373 & 254 & 175 & 115 & -69 & 6.2 & 8.4 & 8.3 & 8.4 & 36 \\
\hline \multicolumn{11}{|l|}{ Males } \\
\hline $0-14 \mathrm{yr}$ & 14 & 7 & 4 & 5 & -62 & 13.6 & 9.5 & 5.7 & 9.5 & -30 \\
\hline $15-24 \mathrm{yr}$ & 587 & 451 & 226 & 137 & -77 & 5.0 & 4.8 & 3.9 & 2.9 & -41 \\
\hline $25-44 \mathrm{yr}$ & 295 & 196 & 142 & 122 & -59 & 5.3 & 8.0 & 7.4 & 7.7 & 46 \\
\hline $45-64 \mathrm{yr}$ & 736 & 490 & 332 & 221 & -70 & 7.2 & 8.6 & 8.3 & 8.6 & 21 \\
\hline $65+y r$ & 1746 & 1711 & 1045 & 917 & -47 & 3.8 & 5.4 & 5.1 & 6.5 & 74 \\
\hline $25-44 \mathrm{yr}$ & 24 & 17 & 13 & 7 & 69 & 9.7 & 9.3 & 4.4 & 8.4 & -13 \\
\hline $45-64 \mathrm{yr}$ & 129 & 88 & 61 & 39 & 70 & 3.7 & 7.1 & 7.5 & 7.3 & 97 \\
\hline $65+y r$ & 114 & 188 & 147 & 103 & 9 & 2.4 & 2.6 & 3.4 & 3.2 & 34 \\
\hline All ages & 35 & 26 & 20 & 12 & 65 & 4.2 & 5.3 & 4.8 & 5.5 & 31 \\
\hline
\end{tabular}


Table 5 Estimated helmet use rate among motorcyclists in each city/county and absolute inequality (between-group variance, BGV), relative inequality (rate ratio between the highest and lowest regions or between the east and north regions) and percentage change between 2002 and 2008 in Taiwan

\begin{tabular}{|c|c|c|c|c|c|c|c|c|c|c|c|c|c|}
\hline & 1997 & 1998 & 1999 & 2000 & 2001 & 2002 & 2003 & 2004 & 2005 & 2006 & 2007 & 2008 & Change \\
\hline Whole of Taiwan & 45 & 72 & 77 & 82 & 89 & 93 & 91 & 91 & 90 & 89 & 89 & 88 & -11 \\
\hline North & 56 & 87 & 81 & 89 & 94 & 96 & 96 & 95 & 94 & 91 & 89 & 86 & -18 \\
\hline Taipei City & 64 & 93 & 95 & 98 & 99 & 99 & 99 & 98 & 97 & 98 & 97 & 97 & -3 \\
\hline Hsinchu City & 24 & 41 & 52 & 60 & 79 & 88 & 90 & 88 & 90 & 87 & 84 & 70 & -75 \\
\hline Keelung City & 37 & 67 & 85 & 89 & 91 & 95 & 88 & 89 & 92 & 94 & 97 & 93 & -5 \\
\hline Taipei County & 38 & 67 & 79 & 85 & 93 & 97 & 98 & 98 & 95 & 87 & 81 & 75 & -58 \\
\hline Taoyuan County & 41 & 65 & 75 & 84 & 92 & 94 & 93 & 92 & 93 & 91 & 93 & 95 & 1 \\
\hline Hsinchu County & 27 & 34 & 57 & 64 & 77 & 84 & 87 & 86 & 85 & 84 & 83 & 87 & 10 \\
\hline Yilan County & 29 & 59 & 65 & 75 & 81 & 91 & 90 & 91 & 92 & 93 & 94 & 96 & 15 \\
\hline Middle & 31 & 55 & 69 & 73 & 85 & 90 & 91 & 90 & 90 & 90 & 90 & 87 & -9 \\
\hline Taichung City & 35 & 56 & 72 & 79 & 92 & 97 & 98 & 98 & 98 & 98 & 98 & 98 & 5 \\
\hline Miaoli County & 18 & 69 & 52 & 65 & 77 & 84 & 80 & 72 & 77 & 76 & 78 & 79 & -27 \\
\hline Taichung County & 33 & 55 & 63 & 74 & 92 & 96 & 95 & 94 & 95 & 92 & 96 & 93 & -10 \\
\hline Changhua County & 19 & 29 & 57 & 70 & 84 & 92 & 93 & 95 & 94 & 93 & 91 & 86 & -32 \\
\hline Nantou County & 16 & 43 & 48 & 52 & 72 & 87 & 90 & 81 & 76 & 81 & 87 & 84 & -15 \\
\hline Yunlin County & 22 & 22 & 33 & 62 & 65 & 74 & 68 & 65 & 61 & 61 & 57 & 56 & -82 \\
\hline South & 42 & 71 & 81 & 81 & 87 & 92 & 88 & 87 & 87 & 87 & 88 & 89 & -7 \\
\hline Kaohsiung City & 44 & 70 & 72 & 83 & 89 & 92 & 89 & 89 & 93 & 96 & 97 & 97 & 11 \\
\hline Chiayi City & 17 & 80 & 93 & 97 & 98 & 98 & 99 & 100 & 99 & 99 & 97 & 90 & -46 \\
\hline Tainan City & 42 & 76 & 85 & 88 & 94 & 97 & 93 & 92 & 94 & 93 & 94 & 95 & -4 \\
\hline Chiayi County & 41 & 36 & 46 & 73 & 76 & 88 & 82 & 80 & 83 & 81 & 80 & 82 & -14 \\
\hline Tainan County & 25 & 41 & 66 & 67 & 81 & 90 & 88 & 87 & 85 & 86 & 88 & 90 & -2 \\
\hline Kaohsiung County & 28 & 41 & 40 & 59 & 79 & 89 & 85 & 84 & 81 & 76 & 77 & 80 & -33 \\
\hline Pingtung County & 31 & 53 & 41 & 53 & 76 & 88 & 86 & 83 & 81 & 80 & 81 & 80 & -27 \\
\hline East & 31 & 59 & 74 & 82 & 88 & 89 & 91 & 90 & 90 & 89 & 91 & 94 & 16 \\
\hline Hualien County & 27 & 64 & 84 & 87 & 92 & 93 & 98 & 94 & 93 & 91 & 93 & 96 & 9 \\
\hline Taitung County & 45 & 51 & 58 & 72 & 86 & 85 & 86 & 86 & 85 & 87 & 90 & 91 & 13 \\
\hline \multicolumn{14}{|l|}{ Inequality } \\
\hline BGV & 169 & 221 & 149 & 168 & 78 & 31 & 48 & 58 & 66 & 69 & 78 & 95 & \\
\hline Highest/lowest & 4.10 & 4.21 & 2.84 & 1.87 & 1.52 & 1.34 & 1.46 & 1.54 & 1.64 & 1.64 & 1.71 & 1.76 & \\
\hline East/North & 0.56 & 0.68 & 0.91 & 0.93 & 0.94 & 0.92 & 0.95 & 0.95 & 0.95 & 0.98 & 1.03 & 1.08 & \\
\hline
\end{tabular}

\section{Enforcement and compliance of motorcycle helmet use}

Despite the possibility of underestimation of the helmet use rate, we still found quite different patterns of change in the motorcycle helmet use rate in different cities/counties. Some cities/counties (Taipei City, Keelung City, Taoyuan County, Yilan County, Taichung County, Kaohsiung City and Tainan City) had persistently high helmet use rates from 2001 through 2008; however, other cities/counties (Hsingchu City, Taipei County, Miaoli County and Yunlin County) had a helmet use rate lower than $80 \%$ in 2008, and Hsingchu City, Taipei County and Yunlin County exhibited a gradual decrease in the helmet use rate since 2002 .

Previous studies have also revealed regional differences in the increase in the helmet use rate after passing of the legislation and the decrease in the helmet use rate several years after the legislation was passed. ${ }^{24}{ }^{25}$ Legislation mandating the use of bicycle helmets by all children younger than 18 years was introduced in the city of East York, Ontario, in October 1995, and an evaluation in 1996 suggested that the effect of the legislation was most powerful among children who resided in low-income areas, the helmet use rate being 33\% in 1995 and increasing to $61 \%$ in $1996 .{ }^{24}$ Sadly, the helmet use rate in middleand low-income areas returned to the prelegislation level $(50 \%$ and $33 \%$, respectively) in 2001, 6 years after introduction of the legislation. ${ }^{25}$

The decline in the helmet use rate several years after passage of the helmet law might be partially due to a decrease in rigorous enforcement of the law by the police and partially due to cyclists' compliance. In most cases, enforcement of traffic laws involves the compliance of individuals in terms of a certain behaviour, such as avoiding speeding or drunk-driving, and the use of restraints in vehicles. ${ }^{3}$ Compliance with these legally prescribed behaviours also varies by socioeconomic status: for example, rear-passenger seatbelt use has been compulsory in the UK since 1991; however, an observational study indicated that only $74 \%$ of rear passengers wear seatbelts, and a 2.2 -fold increase in the wearing of seatbelts was observed between the lowest and highest socioeconomic position (SEP) groups. ${ }^{26}$

The strength of enforcement of the motorcycle helmet law by the police might differ in different cities/counties across Taiwan. Policing behaviour is not as highly structured by law as most people would expect. In reality, the task of individual police officers is to negotiate various uncertainties to achieve a resolution that is optimal for the officer, his/her agency, the citizen(s) involved and the public at large. ${ }^{27}$ Study has also revealed that the collective police culture has an impact on police discretion and varies between large urban and small rural agencies. ${ }^{28}$ Further studies are needed to explore the regional inequality in policing factors across cities/counties in Taiwan.

\section{Policy implications}

As indicated by Margret Whitehead, not all inequalities in health can be described as inequities. ${ }^{29}$ The term inequity refers to inequalities in health that are unnecessary and avoidable. Whitehead classifies only four out of seven determinants of health inequalities as unnecessary and avoidable. Inequalities in 
Table 6 Selected explanatory factors associated with mortality from road traffic injuries in each city/county and percentage change between 1997 and 2008 in Taiwan

\begin{tabular}{|c|c|c|c|c|c|c|c|c|c|}
\hline & \multicolumn{3}{|c|}{ Registered motorcycles per 1000 population } & \multicolumn{3}{|c|}{$\begin{array}{l}\text { Road traffic injuries per } 10000 \\
\text { population }\end{array}$} & \multicolumn{3}{|c|}{ General beds per 100000 population } \\
\hline & 1997 & 2008 & Change & 1997 & 2008 & Change & 1997 & 2008 & Change \\
\hline Whole of Taiwan & 464 & 623 & 34 & 1.3 & 0.9 & -31 & 30 & 32 & 7 \\
\hline North & 413 & 519 & 26 & 1.1 & 0.6 & -45 & 34 & 32 & -6 \\
\hline Taipei City & 335 & 412 & 23 & 0.8 & 0.3 & -63 & 51 & 53 & 3 \\
\hline Hsinchu City & 526 & 636 & 21 & 1.4 & 0.7 & -50 & 30 & 30 & 2 \\
\hline Keelung City & 352 & 482 & 37 & 1.1 & 0.4 & -64 & 39 & 35 & -10 \\
\hline Taipei County & 426 & 580 & 36 & 0.6 & 0.4 & -33 & 14 & 15 & 11 \\
\hline Taoyuan County & 426 & 543 & 28 & 1.2 & 0.7 & -42 & 39 & 35 & -9 \\
\hline Hsinchu County & 435 & 527 & 21 & 2.3 & 1.5 & -35 & 21 & 17 & -18 \\
\hline Yilan County & 498 & 626 & 26 & 2.1 & 1.7 & -19 & 43 & 41 & -6 \\
\hline Middle & 483 & 642 & 33 & 1.4 & 1.1 & -21 & 26 & 30 & 15 \\
\hline Taichung City & 460 & 595 & 29 & 1.3 & 0.6 & -54 & 44 & 51 & 15 \\
\hline Miaoli County & 472 & 615 & 30 & 2.4 & 1.2 & -50 & 25 & 29 & 15 \\
\hline Taichung County & 474 & 637 & 34 & 0.8 & 1.0 & 25 & 20 & 27 & 36 \\
\hline Changhua County & 503 & 677 & 35 & 1.2 & 1.1 & -8 & 22 & 28 & 27 \\
\hline Nantou County & 476 & 646 & 36 & 2.9 & 1.6 & -45 & 26 & 23 & -14 \\
\hline Yunlin County & 484 & 663 & 37 & 1.3 & 1.6 & 23 & 18 & 24 & 37 \\
\hline South & 532 & 757 & 42 & 1.9 & 1.1 & -42 & 32 & 35 & 9 \\
\hline Kaohsiung City & 558 & 790 & 42 & 1.5 & 0.5 & -67 & 44 & 42 & -5 \\
\hline Chiayi City & 576 & 726 & 26 & 1.6 & 0.5 & -69 & 53 & 65 & 24 \\
\hline Tainan City & 547 & 753 & 38 & 4.0 & 0.5 & -88 & 41 & 32 & -22 \\
\hline Chiayi County & 491 & 654 & 33 & 2.0 & 1.9 & -5 & 12 & 25 & 109 \\
\hline Tainan County & 502 & 718 & 43 & 0.9 & 1.5 & 67 & 22 & 24 & 12 \\
\hline Kaohsiung County & 542 & 804 & 48 & 1.5 & 1.3 & -13 & 26 & 28 & 7 \\
\hline Pingtung County & 529 & 774 & 46 & 0.9 & 1.7 & 89 & 29 & 31 & 5 \\
\hline East & 519 & 719 & 39 & 3.7 & 2.0 & -46 & 39 & 38 & -3 \\
\hline Hualien County & 512 & 1025 & 100 & 3.8 & 1.9 & -50 & 46 & 44 & -5 \\
\hline Taitung County & 521 & 511 & -2 & 3.6 & 2.3 & -36 & 32 & 32 & 0 \\
\hline \multicolumn{10}{|l|}{ Inequality } \\
\hline BGV & 4454 & 15055 & & 0.70 & 0.28 & & 175 & 152 & \\
\hline Highest/lowest & 1.72 & 2.49 & & 6.67 & 7.67 & & 4.40 & 4.21 & \\
\hline East/North & 1.26 & 1.39 & & 3.36 & 3.33 & & 1.15 & 1.19 & \\
\hline
\end{tabular}

health due to health-damaging behaviours in which the choice of lifestyle is severely restricted are unnecessary and avoidable. Not wearing a motorcycle helmet is a health-damaging behaviour in which the choice is shaped by social context (strength of enforcement by the police and a law-abiding culture). It is unfair and unjust that the police in different cities/counties enforce the motorcycle helmet law to different degrees, resulting in huge differences in the helmet use rate and ultimately causing large differences in the RTI mortality rate.

To avoid unnecessary RTI deaths and to ensure a high compliance with the helmet use law in every city/county in Taiwan, it is necessary to establish a helmet use surveillance system to identify whether some cities/counties have experienced a decline in the helmet use rate several years after passage of the helmet law. The Department of Police could use this information to urge Police Bureaus in some cities/counties to improve the helmet use rate.

In conclusion, in Taiwan, passage of the motorcycle helmet law reduced the inequality in RTI mortality between regions of differing socioeconomic development. Nevertheless, analysis of helmet use also indicated an increase in inequality in the rate of helmet use across regions 5 years after passage of the law. It is therefore necessary to monitor the helmet use rate after passage of a motorcycle helmet law to ensure the effect of a reduction in regional inequality in RTI mortality.

'All authors have completed the Unified Competing Interest form at http://www.icmje.org/coi_disclosure.pdf (available on request from the corresponding author) and declare that (1) (initials of relevant authors) have support from (name of company) for the submitted work; (2) (initials of relevant authors) have (no or specified) relationships with (name of

\section{What is already known on this subject}

- It has been proven that passage of mandatory motorcycle helmet laws effectively reduces motorcycle head injuries, hospitalisations and deaths.

- However, little is known regarding the effect of motorcycle helmet laws on reducing regional inequality in mortality from road traffic injuries (RTIs).

\section{What this study adds}

- In Taiwan, passage of the motorcycle helmet law reduced the regional inequality in the overall and motorcycle-related RTI mortality.

- However, a resurgence in regional inequality in the helmet use rate 5 years after passage of the helmet law was noted. 


\section{Policy implications}

It is necessary to monitor the helmet use rate after passage of a motorcycle helmet law to ensure the effect of a reduction in regional inequality in $\mathrm{RTI}$ mortality.

companies) that might have an interest in the submitted work in the previous 3 years; (3) their spouses, partners or children have (specified) financial relationships that may be relevant to the submitted work and (4) (initials of relevant authors) have no (or specified) non-financial interests that may be relevant to the submitted work.'

\section{Competing interests None.}

Ethics approval This study was conducted with the approval of the Institution Review Board of National Cheng Kung University Hospital.

Contributors All authors have contributed to the study design, data analysis and interpretation.

Provenance and peer review Not commissioned; externally peer reviewed.

\section{REFERENCES}

1. Machkenbach JP, Bakker MJ; European Network on Interventions and Policies to Reduce Inequalities in Health. Tackling socioeconomic inequalities in health: analysis of European experiences. Lancet 2003;362:1409-14.

2. Vega J, Irwin A. Tackling health inequalities: new approaches in public policy. Bull World Health Organ 2004;82:482-3.

3. White M, Adams J, Heywood P. How and why do interventions that increase health overall widen inequalities within population? In: Babones S, ed. From equity to health: international and interdisciplinary perspectives on the link between social inequality and human health. Nashville: Vanderbilt University Press, 2008.

4. Victora CG, Vaughan JP, Barros FC, et al. Explaining trends in inequality: evidence from Brazil child health studies. Lancet 2000;356:1093-8.

5. Tugwell P, de Savigny D, Hawker G, et al. Applying clinical epidemiological methods to health equity: the equity effectiveness loop. Br Med J 2006;332:358-61.

6. World Health Organization and World Bank. World report on road traffic injury prevention. Geneva: World Health Organization, 2004.

7. Ameratunga S, Hijar M, Norton R. Road-traffic injuries: confronting disparities to address a global-health problem. Lancet 2006;367:1533-40.

8. World Health Organization. Helmets: A road safety manual for decision makers and practitioners. Geneva: World Health Organization, 2006.
9. Minitstry of Transportation and Communication of Taiwan. Number of registered motor vehicles in Taiwan-Fuchien Area, 2009. http://www.motc.gov.tw/ mocwebGIP/wSite/lp?ctNode $=5508 \times$ x $x$ Cat $=14$ (accessed 10 Aug 2010)

10. Keng SH. Helmet use and motorcycle fatalities in Taiwan. Accid Anal Prev 2005; 37:349-55

11. Liu B, Ivers R, Norton R, et al. Helmets for preventing injury in motorcycle riders. Cochrane Database Syst Rev 2004;(2):CD004333.

12. Kraus JF, Peek C, McArthur DL, et al. The effect of the 1992 California motorcycle helmet use law on motorcycle crash fatalities and injuries. JAMA 1994;272:1506-11.

13. Servadei $\mathbf{F}$, Begliomini $\mathbf{C}$, Gardini $\mathbf{E}$, et al. Effect of Italy's motorcycle helmet law on traumatic brain injuries. Inj Prev 2003:9:257-60.

14. Tsai MC, Hemenway D. Effect of the mandatory helmet law in Taiwan. Inj Prev 1999;5:290-1.

15. Chiu WT, Kuo CY, Hung CC, et al. The effect of the Taiwan motorcycle helmet use law on head injuries. Am J Public Health 2000;90:793-6.

16. Chu HF, Wu SC. Comparison of number of deaths released by the registration data of Department of Health and Ministry of Interior: a linkage study (In Chinese). Taiwan J Public Health 2004;23:447-52.

17. Lu TH, Walker S, Anderson RN, et al. The proportion of injury deaths with unspecified external cause codes - a comparison of Australia, Sweden, Taiwan and the United States. Inj Prev 2007;13:276-81.

18. Department of Police. Road traffic injury dataset. Department of Police of Taiwan Taiwan, 1997-2008.

19. Harper S, Lynch J. Measuring health inequalities. In: Oakes JM, Kaufman JS eds. Methods in social epidemiology. San Francisco, CA: Jossey-Bass, 2006

20. Harper S, Lynch J, Meersman SC, et al. An overview of methods for monitoring social disparities in cancer with an example using trends in lung cancer incidence by area-socioeconomic position and race-ethnicity, 1992-2004. Am J Epidemiol 2008;167:889-99.

21. Keppel KG, Pearcy JN. Measuring relative disparities in terms of adverse events. J Public Health Manag Pract 2005;11:479-83.

22. Low A, Low A. Importance of relative measures in policy on health inequalities. $\mathrm{Br}$ Med J 2006:332:967-9.

23. Council for Economic Planning and Development, Executive Yuan, Taiwan. Urban and Regional Development Statistics. http://www.cepd.gov.tw/encontent/en data/ en_list.jsp?linkID=119\&parentLinkID=112 (accessed 20 Dec 2009)

24. Parkin PC, Khambalia A, Kmet L, et al. Influence of socioeconomic status on the effectiveness of bicycle helmet legislation for children: a prospective observation study. Pediatrics 2003;112:e192-6.

25. Macpherson AK, Macarthur C, To TM, et al. Economic disparity in bicycle helmet use by children six years after the introduction of legislation. Inj Prev 2006;12:231-5.

26. Colgan F, Gospel A, Petrie J, et al. Does rear seat belt use vary according to socioeconomic status? J Epidemiol Community Health 2004:58:929-30.

27. Schafer JA. Negotiating order in the policing of youth drinking. Policing 2005;28:279-300.

28. Paoline EA, Terrill W. The impact of police culture on traffic stop searches: an analysis of attitudes and behavior. Policing 2005;28:455-72.

29. Whitehead M. The concepts and principles of equality and health. Copenhagen: World Health Organization, 1990.

\section{Physician arrested for speeding}

A Japanese physician has been arrested after a joy ride in a $\$ 220000$ Ferrari driving at $124 \mathrm{~km} / \mathrm{h}$ in $40 \mathrm{~km} / \mathrm{h}$ zone. The 50 -year-old doctor faces up to six months in jail and a fine of about $\$ 1200$. After posting the escapade on YouTube, local police caught up with him. When arrested, the doctor boasted "I wanted to make a Ferrari promotional video". 